\title{
ANALISIS TATA KELOLA SISTEM INFORMASI AKADEMIK DI PERGURUAN TINGGI SWASTA DI KOTA BANDAR LAMPUNG MENGGUNAKAN KERANGKA KERJA COBIT 4.1
}

\author{
I Nyoman Agus Lasdita \\ 1611050042 \\ Fakultas Bisnis \&Komputer \\ inyomanlasdita.1611050042@mail.darmajaya.ac.id
}

\begin{abstract}
Pengelolaan teknologi informasi merupakan proses dan struktur hubungan yang mengendalikan dan mengarahkan suatu organisasi perusahaan dalam mencapai tujuan organisasi dengan menambahkan nilai agar teknologi informasi dan prosesnya dapat diseimbangkan dengan resikonya. Penelitian ini akan menghasilkan rekomendasi teknologi informasi yang merupakan perkembangan dari teknologi informasi yang berjalan di organisasi saat ini, guna meningkatkan kinerja dari teknologi informasi layanan akademik yang ada di perguruan tinggi swasta yang ada di kota Bandar Lampung, dimana aktivitas dari layanan akademik tersebut menjadi tanggung jawab dari unit pelayanan terpadu dari setiap perguruan tinggi. Perancangan teknologi informasi dalam penelitian ini menggunakan kerangka kerja COBIT 4.1. Penelitian ini membahas 2 domain dari 4 domain yang terdapat pada COBIT dengan pembahasan dibatasi pada tingkat control proses saja. Adapun domain yang dipilih adalah domain Deliver and Support (DS) dan Monitor and Evaluate (ME) yang diperuntukkan membuat rekomendasi pengelolaan teknologi informasi.
\end{abstract}

Kata Kunci : Cobit, domain Deliver and Support (DS), domain Monitor and Evaluate(ME) 


\section{Pendahuluan}

Salah satu kebutuhan yang sangat penting bagi suatu organisasi saat ini adalah Teknologi Informasi (TI), karena dengan adanya teknologi informasi dapat membantu perusahaan dalam meningkatkan efisiensi dan efektifitas dari proses bisnis perusahaan itu sendiri, demikian juga halnya dengan perguruan tinggi. Perguruan tinggi merupakan salah satu instansi yang bergerak pada bidang pendidikan. Dengan demikian agar tercapainya efisiensi dan efektifitas, maka diperlukanlah suat pengelolaan yang baik dan benar terhadap teknologi informasi yang terdapat dalam perusahaan tersebut sehingga diharapkan nantinya teknologi informasi ini mampu menunjang kesuksesan organisasi perusahaan dalam mencapai tujuan.Berhasilnya tata kelola perusahaan saat ini amat bergantung pada sejauh mana tata kelola dari teknologi informasi yang dilakukan. Tata kelola teknologi informasi merupakan bagian yang terkait dengan tata kelola perusahaan, dimana teknologi informasi perusahaan berkaitan dengan bagaimana top manajemen dari perusahaan memperoleh keyakinan bahwa Manajer Sistem Informasi (Chief Information Officer) dan organisasi TI dapat memberikan return atau pengembalian berupa valuebagi perusahaan. Pelayanan dalam bidang akademik adalah salah satu aktivitas utama perguruan tinggi yang berfungsi sebagai penyelenggara pendidikan. Dalam melaksanakan pelayanan ini diperlukanlah Teknologi Informasi yang akan memberikan kemudahan, kecepatan serta kenyamanan sehingga dapat meningkatkan kualitas layanan kepada mahasiswa.

\section{Landasan Teori}

2.1. Teknologi Informasi

Teknologi Informasi adalah istilah terhadap berbagai macam hal dan kemampuan yang digunakan dalam pembentukan, penyimpanan, dan penyebaran informasi. Teknologi informasi tidak hanya terbatas pada teknologi komputer (perangkat keras dan perangkat lunak) yang digunakan untuk memproses dan menyimpan informasi, melainkan juga mencakup teknologikomunikasi untuk mengirimkan informasi.

\subsection{Tata Kelola TI}

Pengertian tata kelola TI yaitu :Tata kelola TI didefinisikan sebagai tanggungjawab eksekutif dan dewan direktur dan terdiri atas kepemimpinan, struktur organisasi serta prosesproses yang memastikan TI perusahaan mendukung dan memperluas obyektif dan strategi organisasi. Tata kelola TI mencakup area terdiri dari kelima fokus area tata kelola 
TI, dua diantaranya: value delivery and risk management merupakan outcome, sedangkan tiga lainnya merupakan driver(pendorong): strategic alignment, resource management dan performance measurement. Program TI akan terdiri atas kebijakan, standar dan prosedur. Berikut ini gambar yang menunjukkan fokus area tata kelola Teknologi Informasi :

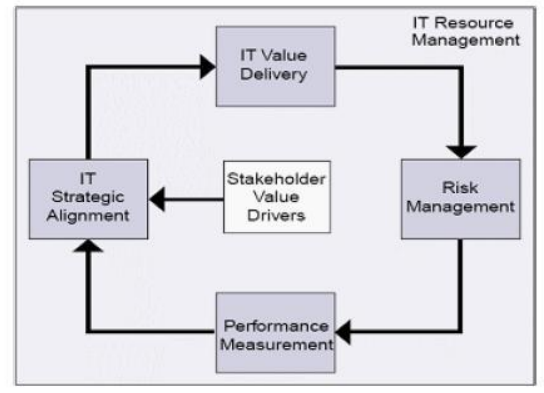

Gambar 1. Fokus Area Tata kelola TI

\subsection{COBIT (Control Objective For Information And Related Technology)}

COBIT dapat diartikan sebagai tujuan pengendalian untuk informasi dan teknologi terkait dan merupakan standar terbuka untuk pengendalian terhadap teknologi informasi yang dikembangkan dan dipromosikan oleh Institut IT Governance. COBIT pertama sekali diperkenalkan pada tahun 1996 adalah merupakan alat (tool) yang disiapkan untuk mengatur teknologi informasi (IT Governance tool). Pada dasarnya kerangka kerja COBIT terdiri dari 3 tingkat control objectives, yaitu activities dan tasks, process, domains.Activities dan tasks merupakan kegiatan rutin yang memiliki konsep daur hidup, sedangkan task merupakan kegiatan yang dilakukan secara terpisah. Selanjutnya kumpulan activity dan task ini dikelompokan ke dalam proses TI yang memiliki permasalahan pengelolaan TI yang sama dikelompokan ke dalam domains, yaitu : 1) Plan and Organize, 2). Acquire and Implement (AI), 3). Deliver and Suport (DS), 4) Monitor and Evaluate (ME).

Untuk mencapai manurity (kematangan) tertentu, COBIT menerapkan model manurity untuk mengontrol proses TI, sehingga manajemen dapat mengetahui dimana posisi organisasi sekarang dan diposisi dimana organisasi ingin berada dan posisi manurity sebuah organisasi terkait dengan keberadaan dan kinerja proses IT Governance yang dapat dikategorikan menjadi enam tingkatan, yaitu :1). Nol (0) Non Existent (Tidak ada), 2). Satu (1) Initial (Inisialisasi), 3). Dua (2) Repeatable, 4).Tiga (3) Defined (Ditetapkan), 5). Empat (4) Managed (diatur), 6). Lima (5) Optimised ( dioptimalisasi).

\section{Metodologi Penelitian}

Tahapan penelitian terdiri dari pengumpulan data dilakukan dengan beberapa teknik yaitu 
survey, wawancara dan observasi langsung.

\subsection{Pengumpulan Data}

Dalam penelitian ini dua jenis data yang dikumpulkan yaitu Data Primer dan Data Sekunder. Data primer adalah data yang diambil langsung dari obyek penelitian atau merupakan data yang berasal dari sumber asli, dan Data Sekunder Dalam penelitian ini adalah dokumen tentang operasional bagian pengolahan data artikel ilmiah, buku-buku yang relevan.

\subsection{Wawancara}

Proses memperoleh keterangan sesuai dengan tujuan penelitian dengan cara tanya jawab. Suatu proses pengumpulan data untuk mengetahui kondisi-kondisi sistem informasi akademik saat ini dan untuk mengetahui proses kegiatan pelaporan akademik.

\subsection{Observasi}

Dalam tahapan ini penulis melakukan pengumpulan data dengan melakukan obeservasi ke Perguruan-perguruan tinggi swasta yang ada di Bandar Lampung untuk mengamati proses sistem informasi akademik terutama yang mendukung integrasi data untuk laporan akademik.

\section{Kesimpulan}

Berdasarkan dari hasil penelitian,dapat disimpulkan bahwa dengan menggunakan framework cobit dapat diketahui tingkat kematangan suatu sistem informasi kademik dari masing-masing perguruan tinggi untuk menentukan target level kematangan sistem informasi akademik di atasnya sehingga memberi model tata kelola sistem informasi akademik yang baik untuk kedepannya sesuai dengan tujuan organisasi. 


\section{A. REFERENCE}

[1] O. M. Febriani and A. S. Putra, "Sistem Informasi Monitoring Inventori Barang Pada Balai Riset Standardisasi Industri Bandar Lampung," J. Inform., vol. 13, no. 1, pp. 90-98, 2014.

[2] A. S. Putra, "Paperplain: Execution Fundamental Create Application With Borland Delphi 7.0 University Of Mitra Indonesia," 2018.

[3] A. S.utra, "2018 Artikel Struktur Data, Audit Dan Jaringan Komputer," 2018.

[4] A. S. Putra, "ALIAS MANAGER USED IN DATABASE DESKTOP STUDI CASE DB DEMOS."

[5] A. S. Putra, "COMPREHENSIVE SET OF PROFESSIONAL FOR DISTRIBUTE COMPUTING."

[6] A. S. Putra, "DATA ORIENTED RECOGNITION IN BORLAND DELPHI 7.0."

[7] A. S. Putra, "EMBARCADERO DELPHI XE 2 IN GPUPOWERED FIREMONKEY APPLICATION."

[8] A. S. Putra, "HAK ATAS KEKAYAAN INTELEKTUAL DALAM DUNIA TEKNOLOGY BERBASIS REVOLUSI INDUSTRI 4.0."

[9] A. S. Putra, "IMPLEMENTASI PERATURAN PERUNDANGAN UU. NO 31 TAHUN 2000 TENTANG DESAIN INDUSTRI BERBASIS INFORMATION TECHNOLOGY."

[10] A. S. Putra,
"IMPLEMENTATION OF PARADOX DBASE."

[11] A.

S.

Putra, "IMPLEMENTATION OF TRADE SECRET CASE STUDY SAMSUNG MOBILE PHONE."

[12] A. S. Putra, "IMPLEMENTATION

PATENT FOR APPLICATION WEB BASED CASE STUDI WWW. PUBLIKLAMPUNG. COM."

[13] A. "IMPLEMENTATION SYSTEM FIRST TO INVENT IN DIGITALLY INDUSTRY."

[14] A. S. Putra, "MANUAL REPORT \& INTEGRATED DEVELOPMENT

ENVIRONMENT BORLAND DELPHI 7.0."

[15] A. S. Putra, "PATENT AS RELEVAN SUPPORT RESEARCH."

[16] A. S. Putra, "PATENT FOR RESEARCH STUDY CASE OF APPLE. Inc."

[17] A. S. Putra, "PATENT PROTECTION FOR APPLICATION INVENT."

[18] A. S. Putra, "QUICK REPORT IN PROPERTY PROGRAMMING."

[19] A. S. Putra, "REVIEW CIRCUIT LAYOUT COMPONENT

REQUIREMENT ON ASUS NOTEBOOK."

[20] A. S. Putra, "REVIEW TRADEMARK PATENT FOR INDUSTRIAL TECHNOLOGY BASED 4.0."

[21] A. S. Putra, "TOOLBAR COMPONENT PALLETTE IN 
OBJECT

ORIENTED

PROGRAMMING."

[22]

A. S. Putra, "WORKING DIRECTORY SET FOR PARADOX 7."

[23] A. S. Putra, "ZQUERY CONNECTION

IMPLEMENTED

PROGRAMMING

STUDI

CASE PT. BANK BCA Tbk."

[24] A. S. Putra, D. R. Aryanti, and I. Hartati, "Metode SAW (Simple Additive Weighting) sebagai Sistem Pendukung Keputusan Guru Berprestasi (Studi Kasus: SMK Global Surya)," in Prosiding Seminar Nasional Darmajaya, 2018, vol. 1, no. 1, pp. 85-97.

[25] A. S. Putra and O. M. Febriani, "Knowledge Management Online Application in PDAM Lampung Province," in Prosiding International conference on Information Technology and Business (ICITB), 2018, pp. 181-187.

[26] A. S. Putra, O. M. Febriani, and B. Bachry, "Implementasi Genetic Fuzzy System Untuk Mengidentifikasi Hasil Curian Kendaraan Bermotor Di Polda Lampung," SIMADA (Jurnal Sist. Inf. dan Manaj. Basis Data), vol. 1, no. 1, pp. 21-30, 2018.

[27] A. S. Putra, H. Sukri, and K. Zuhri, "Sistem Monitoring Realtime Jaringan Irigasi Desa (JIDES) Dengan Konsep Jaringan Sensor Nirkabel," IJEIS (Indonesian J. Electron. Instrum. Syst., vol. 8, no. 2, pp. 221-232.

[28] D. P. Sari, O. M. Febriani, and
A. S. Putra, "Perancangan Sistem Informasi SDM Berprestasi pada SD Global Surya," in Prosiding Seminar Nasional Darmajaya, 2018, vol. 1, no. 1, pp. 289-294. 